\title{
Usefulness of Electrocardiographic Patterns at Presentation to Predict Long-term Risk of Cardiac Death in Patients With Hypertrophic Cardiomyopathy
}

\author{
Elena Biagini, MD, PhD ${ }^{\mathrm{a}}$, Chiara Pazzi, $\mathrm{MD}^{\mathrm{a}}$, Iacopo Olivotto, $\mathrm{MD}^{\mathrm{b}}$, Beatrice Musumeci, $\mathrm{MD}^{\mathrm{c}}$,
} Giuseppe Limongelli, MD ${ }^{\mathrm{d}}$, Giuseppe Boriani, $\mathrm{MD}, \mathrm{PhD}^{\mathrm{a}}$, Giuseppe Pacileo, $\mathrm{MD}^{\mathrm{d}}$, Vittoria Mastromarino, $\mathrm{MD}^{\mathrm{c}}$, Maria Letizia Bacchi Reggiani, $\mathrm{BSc}^{\mathrm{a}}$, Massimiliano Lorenzini, $\mathrm{MD}^{\mathrm{a}}$, Francesco Lai, MD ${ }^{\mathrm{a}}$, Alessandra Berardini, MD ${ }^{\mathrm{a}}$, Francesca Mingardi, MD ${ }^{\mathrm{a}}$, Stefania Rosmini, MD, PhD ${ }^{\mathrm{a}}$, Elvira Resciniti, $\mathrm{MD}^{\mathrm{a}}$, Claudia Borghi, MD, $\mathrm{PhD}^{\mathrm{a}}$, Camillo Autore, $\mathrm{MD}^{\mathrm{c}}$, Franco Cecchi, $\mathrm{MD}^{\mathrm{b}}$, and Claudio Rapezzi, $\mathrm{MD}^{\mathrm{a}, *}$

\begin{abstract}
The objective of this study was to investigate the prognostic significance of 12-lead electrocardiogram (ECG) patterns in a large multicenter cohort of patients with hypertrophic cardiomyopathy; 1,004 consecutive patients with hypertrophic cardiomyopathy and a recorded standard ECG (64\% men, mean age $50 \pm 16$ years) were evaluated at 4 Italian centers. The study end points were sudden cardiac death (SCD) or surrogates, including appropriate implanted cardiac defibrillator discharge and resuscitated cardiac arrest and major cardiovascular events (including SCD or surrogates and death due to heart failure, cardioembolic stroke, or heart transplantation). Prevalence of baseline electrocardiographic characteristics was: normal ECG 4\%, ST-segment depression 56\%, pseudonecrosis waves $33 \%$, "pseudo-ST-segment elevation myocardial infarction (STEMI)" pattern 17\%, QRS duration $\geq 120 \mathrm{~ms} 17 \%$, giant inverted $\mathrm{T}$ waves $6 \%$, and low QRS voltages $3 \%$. During a mean follow-up of $7.4 \pm 6.8$ years, 77 patients experienced SCD or surrogates and 154 patients experienced major cardiovascular events. Independent predictors of SCD or surrogates were unexplained syncope (hazard ratio [HR] 2.5, 95\% confidence interval [CI] 1.4 to $4.5, \mathrm{p}=0.003$ ), left ventricular ejection fraction $<50 \%$ (HR 3.5, 95\% CI 1.9 to $6.7, \mathrm{p}=$ 0.0001 ), nonsustained ventricular tachycardia (HR 1.7, 95\% CI 1.1 to $2.6, \mathrm{p}=0.027$ ), pseudo-STEMI pattern (HR 2.3, 95\% CI 1.4 to $3.8, \mathrm{p}=0.001$ ), QRS duration $\geq 120 \mathrm{~ms}$ (HR $1.8,95 \%$ CI 1.1 to $3.0, p=0.033$ ), and low QRS voltages (HR 2.3, 95\% CI 1.01 to $5.1, p=$ 0.048). Independent predictors of major cardiovascular events were age (HR 1.02, 95\% CI 1.01 to $1.03, \mathrm{p}=0.0001$ ), $\mathrm{LV}$ ejection fraction $<50 \%$ (HR 3.73, 95\% CI 2.39 to $5.83, \mathrm{p}=$ 0.0001), pseudo-STEMI pattern (HR $1.66,95 \%$ CI 1.13 to $2.45, \mathrm{p}=0.010$ ), QRS duration $\geq 120 \mathrm{~ms}$ (HR $1.69,95 \%$ CI 1.16 to $2.47, \mathrm{p}=0.007$ ), and prolonged QTc interval (HR 1.68, $95 \%$ CI 1.21 to $2.34, p=0.002$ ). In conclusion, a detailed qualitative and quantitative electrocardiographic analyses provide independent predictors of prognosis that could be integrated with the available score systems to improve the power of the current model.

2016 Elsevier Inc. All rights reserved. (Am J Cardiol 2016;ш:ロ-匹)
\end{abstract}

Hypertrophic cardiomyopathy (HC) is the most common genetic cardiac disease and one of the main causes of sudden cardiac death (SCD) in the young. Different noninvasive clinical and instrumental markers, derived from observational

\footnotetext{
${ }^{a}$ Cardiology, Department of Experimental Diagnostic and Specialty Medicine, Alma Mater Studiorum, University of Bologna, Bologna, Italy; ${ }^{\mathrm{b}}$ Cardiothoracovascular Department, Referral Center for Myocardial Diseases, Azienda Ospedaliera Universitaria Careggi, Florence, Italy; ${ }^{\mathrm{c} D e}$ partment of Clinical and Molecular Medicine, Sapienza University of Rome, Rome, Italy; and ${ }^{\mathrm{d}}$ Department of Cardiology, Monaldi Hospital, University of Naples, Naples, Italy. Manuscript received February 25, 2016; revised manuscript received and accepted May 4, 2016.

See page 7 for disclosure information.

*Corresponding author: Tel: (+39) 051-349858; fax: (+39) 051344859 .

E-mail address: claudio.rapezzi@unibo.it (C. Rapezzi).
}

cohort studies, have been related to worse prognosis. However, risk stratification is still largely unsatisfactory because of the low positive predictive value of these predictors. ${ }^{1,2}$ In recent years, the standard electrocardiogram (ECG) has been shown to provide useful prognostic indications in patients with HC. A normal ECG is generally associated with a mild phenotype and favorable outcome, whereas marked electrocardiographic abnormalities have been shown to be correlated with severe hypertrophy and the presence of myocardial fibrosis. ${ }^{3,4}$ However, this universally available, low-cost, and reproducible technique has rarely been tested in multivariable models for SCD and major cardiovascular events' risk stratification. ${ }^{3-5}$ In the present study, we aimed to conduct an extensive qualitative and quantitative electrocardiographic analysis to assess the independent long-term predictive value of specific ECG patterns for prognosis in a large, multicenter $\mathrm{HC}$ cohort. 


\section{Methods}

In this retrospective observational study, we analyzed 1,047 consecutive patients evaluated from 1981 to 2011 at 4 Italian centers (S. Orsola-Malpighi Hospital, University of Bologna, Bologna, Italy [ $\mathrm{n}=452]$, Sapienza University of Rome, Rome, Italy [ $\mathrm{n}=296]$, Azienda Ospedaliera Careggi, Florence, Italy [ $\mathrm{n}=233$ ], Monaldi Hospital, University of Naples, Naples, Italy [n $=66]$ ) with unequivocal diagnosis of HC and a good-quality 12-lead ECG obtained at first evaluation. $\mathrm{HC}$ was diagnosed by the presence of hypertrophied and nondilated left ventricle (wall thickness $\geq 15 \mathrm{~mm}$ in adults) at transthoracic echocardiogram, in the absence of other cardiac or systemic conditions that could produce a comparable magnitude of LV hypertrophy. ${ }^{2}$ Forty-three patients $(4 \%)$ were excluded for the following reasons: (1) inadequate technical electrocardiographic quality $(\mathrm{n}=14)$; (2) presence of paced ventricular rhythm $(\mathrm{n}=15)$; and (3) percutaneous septal alcohol ablation or myectomy preceding first evaluation $(\mathrm{n}=14)$. Therefore, 1,004 patients constituted the final study population.

The study end points were (1) SCD or surrogates, defined as unexpected collapse occurring $<1$ hour from the onset of symptoms in a patient who had previously experienced a relatively uneventful clinical course or unexpected unwitnessed death or aborted cardiac arrest or appropriate implantable cardioverter defibrillator (ICD) therapy (for ventricular tachycardia/fibrillation with a heart rate $\geq 200$ beats/min). ${ }^{6}$ (2) Major cardiovascular events, defined as SCD or surrogates, death due to heart failure or cardioembolic stroke, or heart transplantation. ${ }^{6}$ Follow-up was obtained by scheduled or nonscheduled clinical evaluations. For patients who had not been evaluated clinically for $>1$ year, follow-up was obtained by telephone interview or by contacting the general practitioner.

The scalar 12-lead ECGs (standard calibration $10 \mathrm{~mm} /$ $1 \mathrm{mV}$ ) at first evaluation were performed on commercially available instruments in the supine position during quiet respiration and recorded at a paper speed of $25 \mathrm{~mm} / \mathrm{s}$. The following parameters were measured: PR interval, QRS duration, QRS voltages, QT interval, and corrected QT interval (Bazett's formula). Left bundle branch block (LBBB) or right bundle branch block, left anterior fascicular block, and nonspecific intraventricular conduction disturbance were classified according to international criteria. ${ }^{7}$ A number of electrocardiographic criteria proposed for the clinical identification of LV hypertrophy were used, including Cornell voltage score (SV3 $+\mathrm{R}$ aVL $\geq 20 \mathrm{~mm}$ in women and $\geq 28 \mathrm{~mm}$ in men), modified Sokolow-Lyon score (SV1 or SV2 + RV5 or RV6 $\geq 35 \mathrm{~mm}$ ), the amplitude of R wave in aVL $(\geq 11 \mathrm{~mm})$, and the sum of RDI and SDIII $(\geq 25 \mathrm{~mm})$. LV hypertrophy was diagnosed in the presence of at least 1 criteria. ${ }^{8,9}$ Massive LV hypertrophy was defined by modified Sokolow-Lyon score $\geq 50 \mathrm{~mm}$.

We defined specific ECG patterns. Pseudo-necrosis: presence of $Q$ waves $\geq 1 / 3$ of the ensuing $R$ wave in depth and/or $\geq 0.04$ seconds in duration in at least 2 contiguous leads except $\mathrm{aVR}$ and/or the lack of progressive R-wave voltage increase in the precordial leads. ${ }^{10}$ Low voltages: QRS complex amplitude $<0.5 \mathrm{mV}$ in all limb leads. ${ }^{11}$ Repolarization abnormalities: STsegment depression/elevation $\geq 0.1 \mathrm{mV}$ below or above the baseline at the J-point in at least 2 leads, except V1-V2-V3, where it was considered only when $\geq 0.2 \mathrm{mV} .^{12} \mathrm{~T}$ waves were defined as (1) "inverted" when the negative T-wave amplitude was $\geq 0.1 \mathrm{mV}$, (2) "giant negative" when amplitude was $\geq 1.0 \mathrm{mV},{ }^{12}$ and (3) "giant positive" $\mathrm{T}$ waves were defined as symmetrical positive $\mathrm{T}$ waves $\geq 1.0 \mathrm{mV}{ }^{13}$ ST-segment elevation and giant positive $T$ waves were considered only in the absence of LBBB. The presence of notching in terminal part of QRS was defined as "J wave." A specific ECG pattern characterized by the presence of ST-segment elevation and/or giant positive $\mathrm{T}$ waves in at least 2 contiguous leads in the absence of LBBB was assessed and defined "pseudo-STsegment elevation myocardial infarction (STEMI)" pattern for its resemblance of the ECG associated with the acute/subacute phase of myocardial infarction (Figure 1). ${ }^{14}$ Other prespecified ECG patterns such as massive LV hypertrophy, massive LV hypertrophy associated with right atrial enlargement, and LV hypertrophy with abnormal R/S in V1 were assessed. All ECGs were independently analyzed using manual calipers, and patterns were adjudicated by 2 independent investigators (EB and $\mathrm{CP}-$ S.Orsola Malpighi Hospital Bologna) unaware of the clinical details of the patients. Discrepancies were resolved by a senior supervisor (CR).

Standard M-mode and 2-dimensional echocardiographic studies were performed by commercially available instruments to identify and qualify morphologic features of the left ventricle. The greatest wall thickness measured at any site in the LV wall was regarded as the maximal thickness, ${ }^{6}$ independently of body surface area and gender or age. LV outflow obstruction in basal conditions was defined as a peak outflow gradient of $\geq 30 \mathrm{~mm} \mathrm{Hg}$, as estimated by continuous-wave Doppler echocardiography. ${ }^{15}$

Continuous data were expressed as mean value \pm SD. Data were compared by the chi-square analysis for proportions and Student's $t$ test for continuous variables. Survival rates were obtained using Kaplan-Meier method of estimation. Univariate and multivariable Cox proportional hazard regression models were constructed to identify independent predictors of follow-up events. Each electrocardiographic variable was assessed by Cox proportional univariate survival analysis. Model building followed a backward stepwise approach with entry set at a significance level of 0.1 . For each variable, the hazard ratio (HR) with a corresponding $95 \%$ confidence interval was reported. Harrell's $\mathrm{C}$ index was used to assess model's discrimination. A $\mathrm{p}$ value $<0.05$ was considered statistically significant. Statistical analyses were obtained using Stata/SE 13.1 (StataCorp IP, College Station, Texas).

\section{Results}

Clinical and echocardiographic characteristics and arrhythmic risk profile of the study population are listed in Table 1. In our population, 29 patients had an ICD at first evaluation and 150 underwent ICD implantation during follow-up.

Electrocardiographic variables are listed in Table 2. The pseudo-STEMI pattern was present in 171 patients (17\%) including 97 patients with ST-segment elevation, 34 with giant positive $\mathrm{T}$ waves, and 40 with both. One hundred twenty-one patients $(71 \%)$ showed this pattern in anterior 

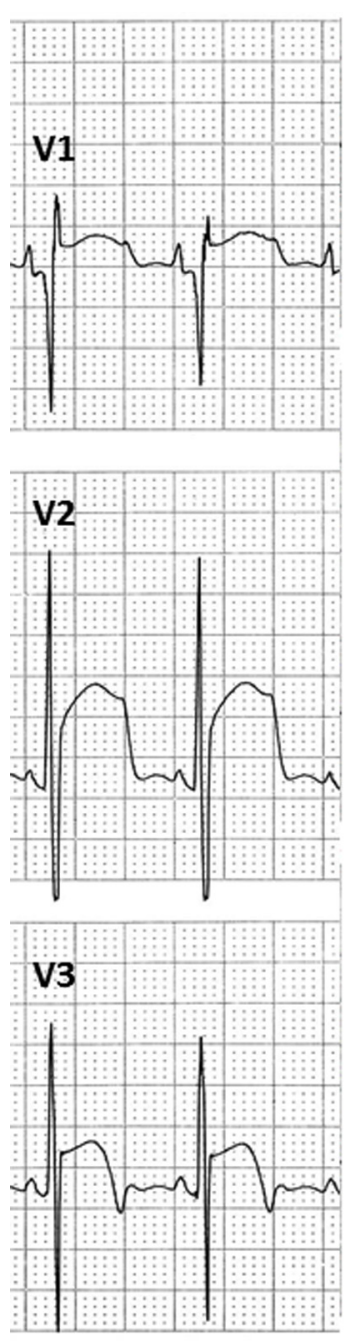
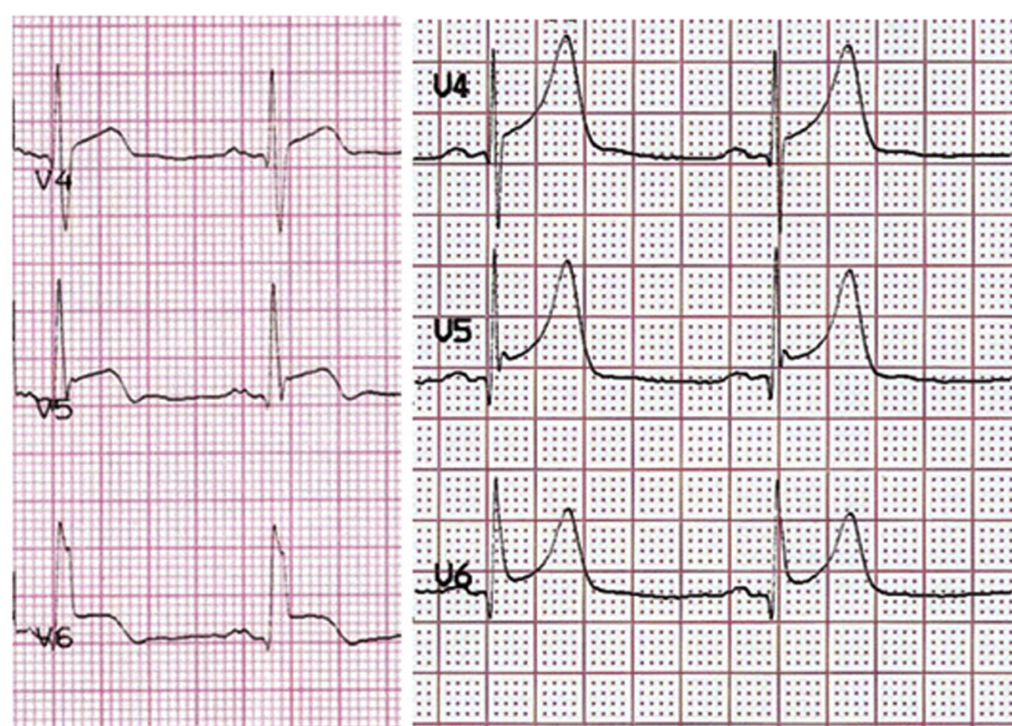

:05:
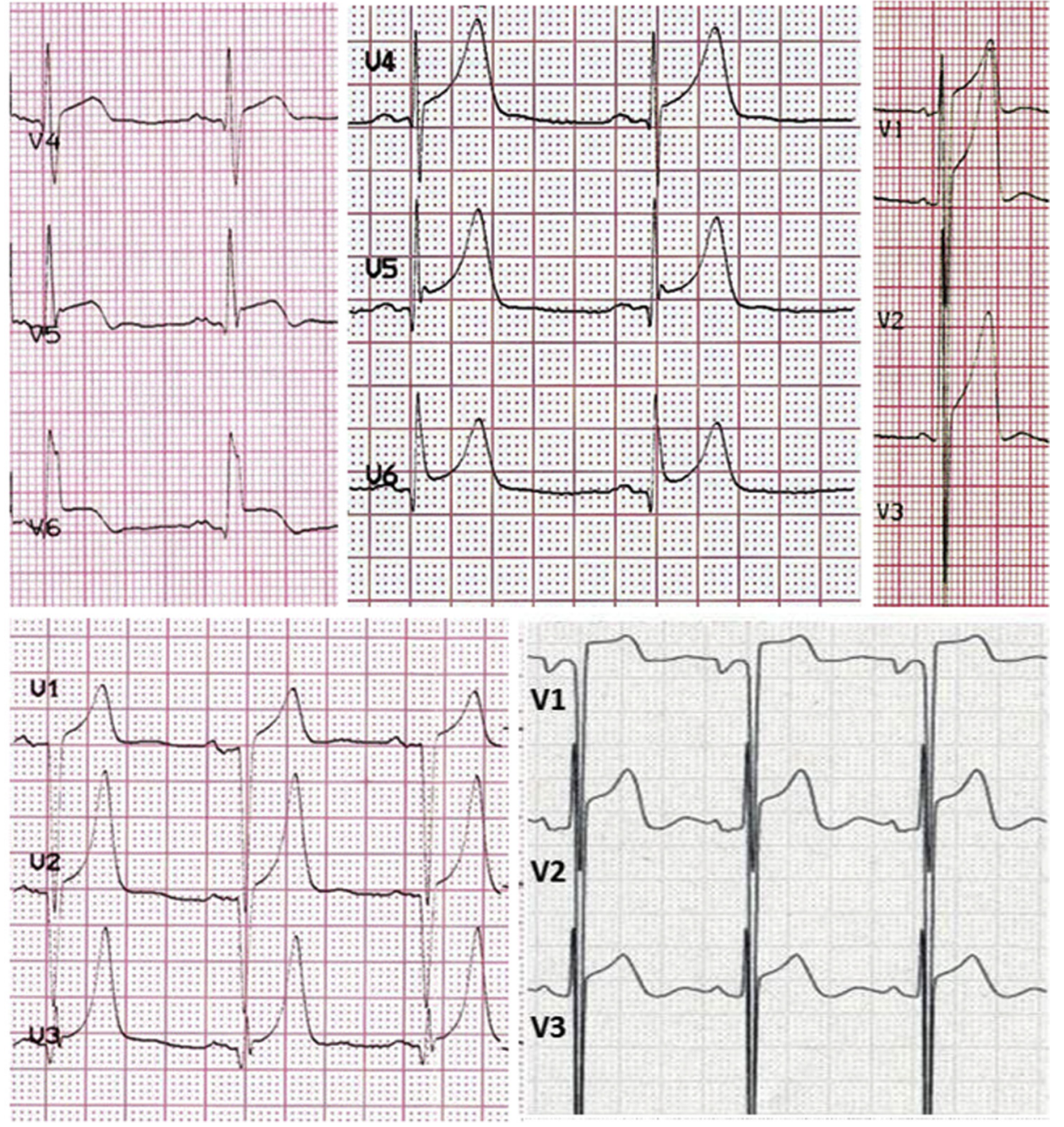

Figure 1. Electrocardiographic examples of the pseudo-STEMI pattern.

leads, 27 patients (16\%) in inferior leads, 15 patients (9\%) in inferolateral leads, and 8 patients $(5 \%)$ only in lateral leads. A short PR interval $(\leq 120 \mathrm{~ms})$ was present in 71 cases.

After a mean follow-up of $7.4 \pm 6.8$ years, 77 patients experienced SCD or surrogates including 41 who actually died suddenly (4\%), 24 with appropriate ICD discharge (2\%), and 12 with aborted cardiac arrest (1\%). A total of 154 patients $(15 \%)$ experienced major cardiovascular events, including the 77 with SCD or surrogates, $60(6 \%)$ with heart failure-related death (15 of which underwent heart transplantation), and 17 (2\%) who died after cardioembolic stroke. The electrocardiographic findings associated with SCD or surrogates at univariate analysis were QRS $\geq 120$ $\mathrm{ms}$, pseudo-STEMI pattern, ST-segment elevation, and low QRS voltages (Table 3). The electrocardiographic findings associated with major cardiovascular events at univariate analysis were QRS $\geq 120 \mathrm{~ms}$, prolonged corrected QT interval, left and right atrial enlargement, and pseudo-STEMI pattern (Table 3).

At multivariable analysis (Table 4), unexplained syncope (hazard ratio [HR] 2.47, 95\% confidence interval [CI] 1.37 to $4.47, \mathrm{p}=0.003$ ), nonsustained ventricular tachycardia
(NSVT) during Holter monitoring (HR 1.68, 95\% CI 1.06 to $2.65, \mathrm{p}=0.027$ ), LV ejection fraction $<50 \%$ (HR 3.55, 95\% CI 1.89 to $6.66, \mathrm{p}=0.0001)$, pseudo-STEMI pattern (HR 2.28, 95\% CI 1.38 to $3.77, \mathrm{p}=0.001$ ), QRS duration $\geq 120 \mathrm{~ms}$ (HR $1.78,95 \%$ CI 1.05 to $3.03, \mathrm{p}=0.033$ ), and low QRS voltages (HR 2.26, 95\% CI 1.01 to 5.07, p = 0.048 ) were independently associated with SCD or surrogates. Harrell's C index was 0.68 . Sensibility and specificity of QRS duration in predicting SCD were $26 \%$ and $84 \%$, respectively; positive and negative predictive values were $12 \%$ and $93 \%$, respectively. Sensibility and specificity of pseudo-STEMI pattern in predicting SCD were $30 \%$ and $84 \%$, respectively; positive and negative predictive values were $13 \%$ and $93 \%$, respectively. Sensibility and specificity of low QRS voltages in predicting SCD were 9\% and 97\%, respectively; positive and negative predictive values were $21 \%$ and $93 \%$ respectively.

Multivariable Cox proportional model for major cardiovascular events (Table 4) identified age (HR 1.02, 95\% CI 1.01 to $1.03, \mathrm{p}=0.0001$ ), $\mathrm{LV}$ ejection fraction $<50 \%$ (HR $3.73,95 \%$ CI 2.39 to $5.83, \mathrm{p}=0.0001$ ), pseudo-STEMI pattern (HR 1.66, 95\% CI 1.13 to $2.45, \mathrm{p}=0.010)$, QRS 
Table 1

Baseline characteristics of the study population $(n=1004)$

Variable

- Age $\geq 18$

- Age 14-17

Males

Age (years), mean $\pm \mathrm{SD}$

Family history of $\mathrm{HC}$

Family history of SCD

LV outflow tract obstruction $(\geq 30 \mathrm{mmHg})$

Unexplained syncope

NSVT on Holter monitoring

NYHA functional class III-IV

Maximal LV wall thicknes (mm) mean $\pm \mathrm{SD} / \mathrm{n}$ patients*

$\mathrm{LV}$ end-diastolic dimension, $(\mathrm{mm})$ mean $\pm \mathrm{SD} / \mathrm{n}$ patients*

LV ejection fraction $<50 \%$

Dilated-hypokinetic evolution

$\mathrm{HC}=$ hypertrophic cardiomyopathy; $\mathrm{LV}=$ left ventricle; $\mathrm{NYHA}=\mathrm{New}$ York Heart Association; NSVT = nonsustained ventricular tachycardia; SCD = sudden cardiac death.

* Data missing: n patients with available data.

duration $\geq 120 \mathrm{~ms}$ (HR $1.69,95 \%$ CI 1.16 to $2.47, \mathrm{p}=$ 0.007), and prolonged QTc interval (HR 1.68, 95\% CI 1.21 to $2.34, \mathrm{p}=0.002$ ) as independent predictors. Harrell's $\mathrm{C}$ index was 0.71 .

Kaplan-Meier survival curves for the end point SCD or surrogates in patients with and without the pseudo-STEMI pattern and QRS duration $\geq 120 \mathrm{~ms}$ are reported in Figure 2. Survival curves were also constructed stratifying the patients according to the number of risk factors $(n=0$, $\mathrm{n}=1, \mathrm{n} \geq 2$ ). In Figure 2, patients were stratified according to the presence of the 4 conventional risk factors for SCD (family history of SCD, unexplained syncope, NSVT during 24-hour Holter monitoring, and maximal LV wall thickness $\geq 30 \mathrm{~mm}$ ). The annual SCD event rate in patients with no risk factors was $0.62 \%, 1.19 \%$ in patients with 1 risk factor, and $1.92 \%$ in patients with $\geq 2$ risk factors (log-rank test $p$ value $=0.0006$ ). The addition of the 3 electrocardiographic variables independently related to SCD improved the model (Figure 2). In patients with no risk factors, the annual SCD event rate was $0.38 \%$ and was $0.91 \%$ and $1.94 \%$ in patients with 1 and $\geq 2$ risk factors, respectively (log-rank test $\mathrm{p}$ value $=0.00001)$. The Cox proportional hazard regression model stratified the patients well according to the number of the conventional risk factors; however, the addition of the electrocardiographic variables in a second model resulted in a higher predictive power for SCD (chi-square from 14 to 32 , $\mathrm{p}$ value 0.0001 ).

\section{Discussion}

This study highlights the potential contribution of standard ECG-interpreted with a quantitative and qualitative approach-to risk stratification of patients with $\mathrm{HC}$. Different ECG patterns can be observed and their recognition can contribute to guide the physician toward a correct differential diagnosis and to stratify the risk of SCD and major cardiovascular events. ${ }^{3,4}$
Table 2

Baseline electrocardiographic characteristics of the study population

\begin{tabular}{lc}
\hline Characteristics & Prevalence \\
\hline Normal ECG & $38(4 \%)$ \\
QRS duration $\geq 120 \mathrm{msec}$ & $172(17 \%)$ \\
Prolonged corrected QT interval $(\geq 440 \mathrm{msec})$ & $297(30 \%)$ \\
Prolonged corrected QT interval $(\geq 480 \mathrm{msec})$ & $65(6 \%)$ \\
Left atrial enlargement & $448(45 \%)$ \\
Right atrial enlargement & $85(8 \%)$ \\
LV hypertrophy* & $562(56 \%)$ \\
Massive LV hypertrophy & $139(14 \%)$ \\
Massive LV hypertrophy associated to right & $11(1 \%)$ \\
$\quad$ atrial enlargement & \\
LV hypertrophy in presence of abnormal R/S in V1 & $23(2 \%)$ \\
Low QRS voltages & $33(3 \%)$ \\
Pseudo-necrosis Q waves & $335(33 \%)$ \\
Repolarisation abnormalities & $778(77 \%)$ \\
Negative T wave & $746(74 \%)$ \\
Giant inverted T waves $(\geq 10$ mm) & $56(6 \%)$ \\
Giant positive T waves $(\geq 10$ mm) & $74(7 \%)$ \\
ST-segment depression & $557(56 \%)$ \\
ST-segment elevation & $137(14 \%)$ \\
"Pseudo-STEMI" pattern & $171(17 \%)$ \\
ST segment elevation without giant positive T waves & $97(10 \%)$ \\
Giant positive T waves without ST segment elevation & $34(3 \%)$ \\
ST segment elevation and giant T waves & $40(4 \%)$ \\
J wave & $34(3 \%)$ \\
Abnormal R/S wave in V1 & $60(6 \%)$ \\
Complete RBBB & $67(7 \%)$ \\
Complete LBBB & $63(6 \%)$ \\
Unspecified intraventricular block & $73(7 \%)$ \\
Left anterior fascicular block & $133(13 \%)$ \\
\hline & \\
&
\end{tabular}

$\mathrm{ECG}=$ electrocardiogram; $\mathrm{HC}=$ hypertrophic cardiomyopathy; $\mathrm{LV}=$ left ventricle; NSVT $=$ non sustained ventricular tachycardia.

* At least 1 criteria satisfied.

The proportion of our cases with normal ECG (4\%) is similar with that reported from other groups. "Repolarization abnormalities" was the commonest single abnormality (77\%), followed by LV hypertrophy $(56 \%)$, left atrial enlargement $(45 \%)$, and pseudonecrosis Q waves $(33 \%)$. Interestingly, some patterns were observed, including pathologic Q waves with positive $\mathrm{T}$ waves in the same lead ("Q/T discordance," 24\%), tall $\mathrm{R}$ waves in V1-V2 $(\mathrm{R} \geq \mathrm{S})$ in the context of LV hypertrophy $(6 \%)$, right atrial enlargement and LV hypertrophy (2\%), giant negative $\mathrm{T}$ waves in the precordial leads (1\%), low QRS voltages (3\%), and pseudoSTEMI pattern (17\%). The relation between ECG and prognosis in $\mathrm{HC}$ has been investigated with conflicting results in the past. $^{3-5,16-22}$ Studies have focused mainly on the degree of LV hypertrophy and the overall electrical instability, expressed by QT duration and dispersion and by T-wave complexity. ${ }^{16-22}$ The sole presence of an "abnormal ECG" has been found to be associated with a more severe HC phenotype and worse cardiovascular outcomecompared with a normal ECG-in 2,485 patients with $\mathrm{HC}^{3}$

The main finding of our study is that specific features of the standard ECG, namely QRS duration $\geq 120 \mathrm{~ms}$, pseudoSTEMI pattern, and low QRS voltages, are independent risk factors for SCD or surrogates (Table 4) and could be usefully integrated with the traditional risk factors (Figure 2). Whereas pseudo-STEMI pattern and QRS duration $>120 \mathrm{~ms}$, together 
Table 3

Univariate analysis in the overall population

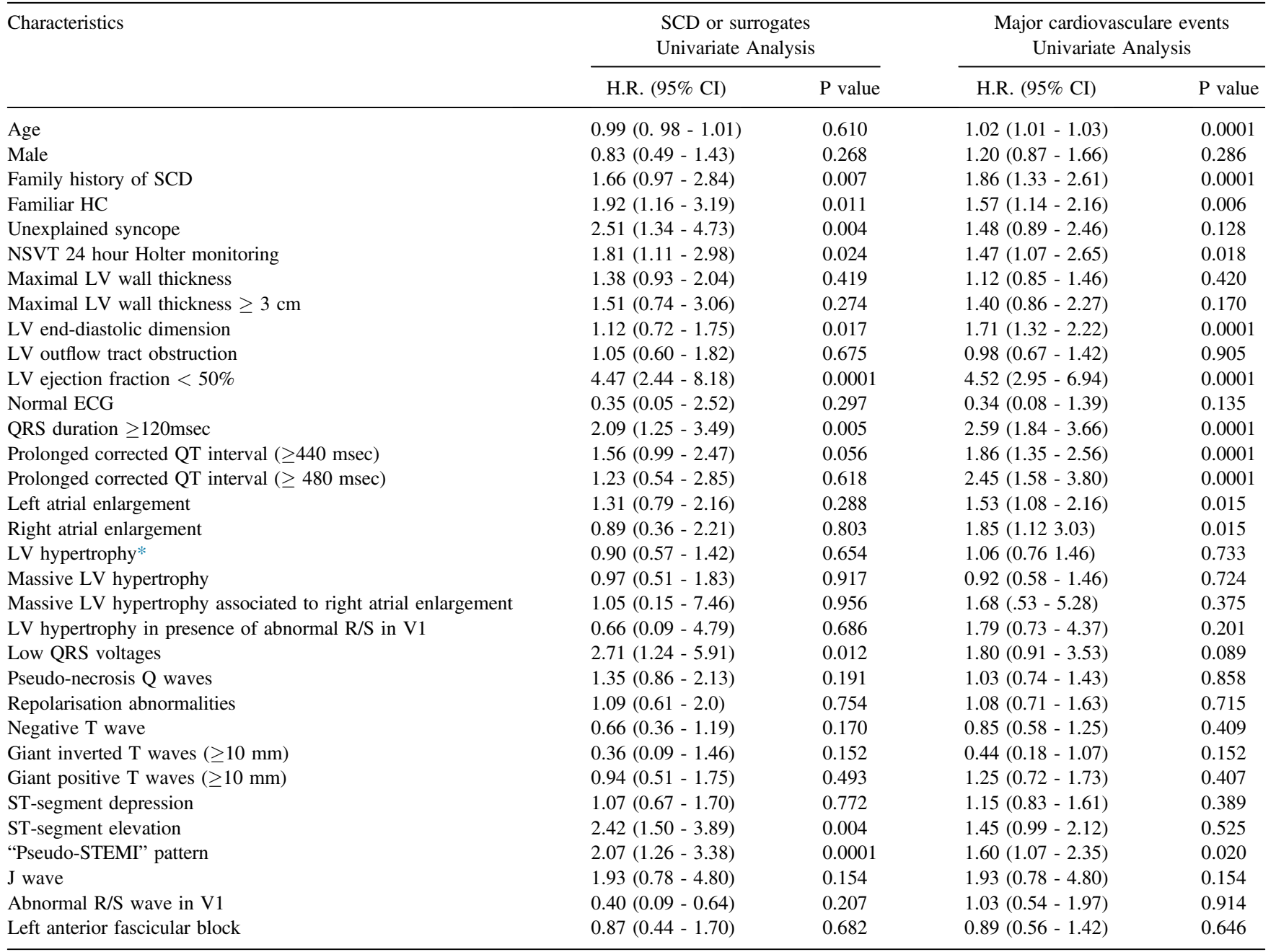

$\mathrm{ECG}=$ electrocardiogram; $\mathrm{HC}=$ hypertrophic cardiomyopathy $\mathrm{LV}=$ left ventricle; $\mathrm{NSVT}=$ non sustained ventricular tachycardia; $\mathrm{SCD}=$ sudden cardiac death.

* At least 1 criteria satisfied.

Table 4

Multivariate analysis in the overall population

\begin{tabular}{llcr}
\hline Variables & \multicolumn{1}{c}{$\begin{array}{c}\text { SCD or surrogates } \\
\text { Multivariable analysis }\end{array}$} & P value & $\begin{array}{c}\text { Major cardiovascular events } \\
\text { Multivariable analysis }\end{array}$ \\
\cline { 2 - 4 } & H.R. $(95 \%$ CI $)$ & & H.R. (95\% CI) \\
\hline Age & $2.47(1.37-4.47)$ & 0.003 & $1.02(1.01-1.03)$ \\
Unexplained syncope & $1.68(1.06-2.65)$ & 0.027 & 0.0001 \\
NSVT 24 hour Holter monitoring & $3.55(1.89-6.66)$ & 0.0001 & $3.73(2.39-5.83)$ \\
LV ejection fraction $<50 \%$ & $1.78(1.05-3.03)$ & 0.033 & $1.69(1.16-2.47)$ \\
QRS duration $\geq 120$ msec & $2.26(1.01-5.07)$ & 0.048 & 0.0001 \\
Low QRS voltages & $2.28(1.38-3.77)$ & 0.001 & $1.66(1.13-2.45)$ \\
"Pseudo STEMI" pattern & & & $1.68(1.21-2.34)$ \\
Prolonged QTc interval $(\geq 440 \mathrm{msec})$ & & 0.007 \\
\hline
\end{tabular}

$\mathrm{LV}=$ left ventricle; NSVT $=$ non sustained ventricular tachycardia; $\mathrm{SCD}=$ sudden cardiac death.

with prolonged QTc interval, were found to be independent predictors not only of SCD and surrogates but of all the major cardiovascular events, they have been analyzed in detail.
The negative prognostic role of prolonged QRS duration is somewhat expected and, indeed, has been reported by Bongioanni et $\mathrm{al}^{16}$ as regard to HC-related death. ${ }^{5}$ An 

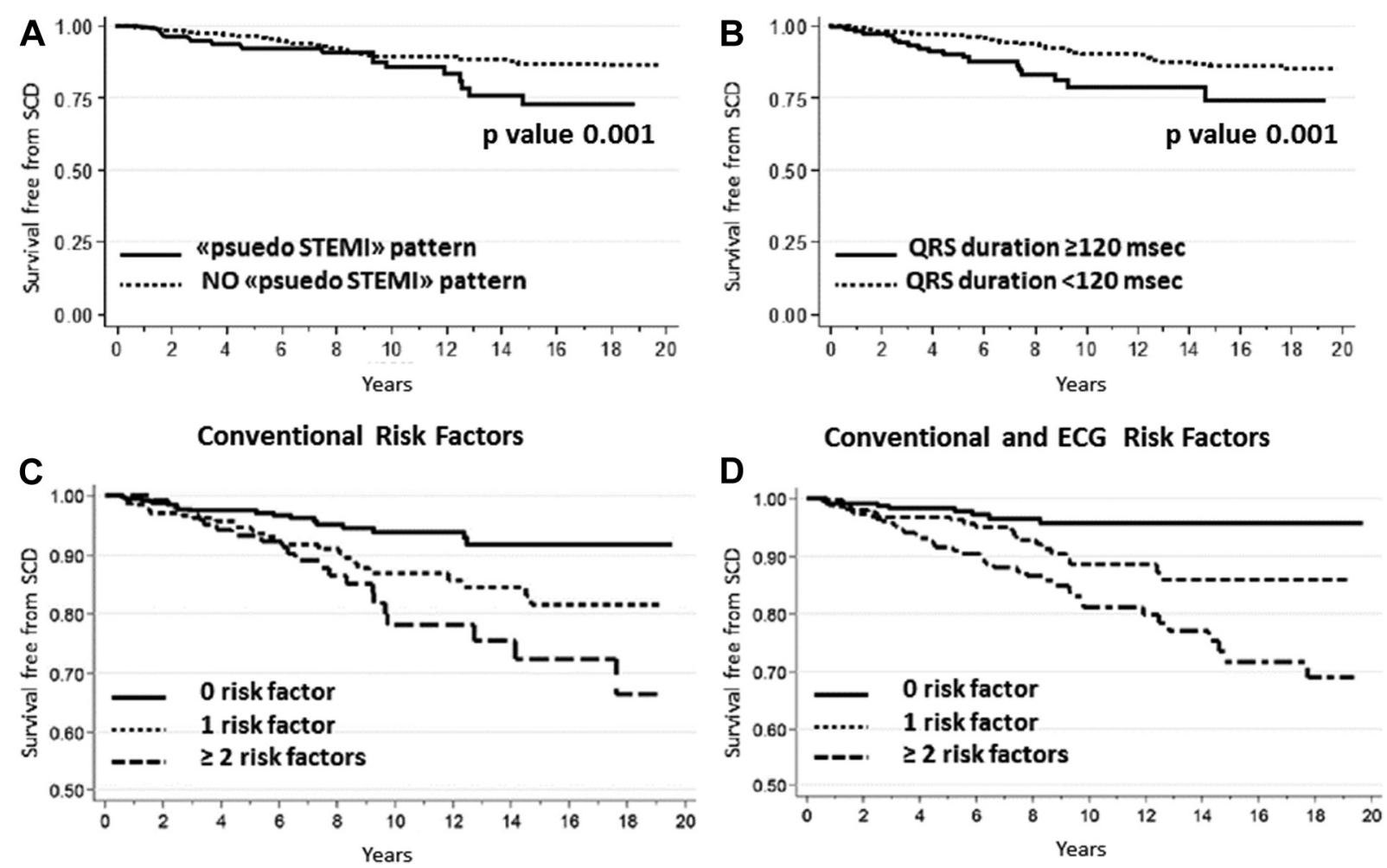

Figure 2. Kaplan-Meier survival curves for the end point SCD or surrogates according to the presence/absence of the pseudo-STEMI pattern (panel A) and QRS duration $\geq 120 \mathrm{~ms}$ (panel $B$ ). (Panels $C$ and $D$ ) Kaplan-Meier survival curves for the end point SCD or surrogates stratifying the patients according to the number of conventional risk factors (family history of SCD, unexplained syncope, nonsustained ventricular tachycardia during electrocardiographic Holter monitoring, maximum wall thickness $\geq 30 \mathrm{~mm}$ ), or after the addition of the 3 ECG patterns (pseudo-STEMI pattern, QRS duration $\geq 120 \mathrm{~ms}$, and low QRS voltages).

association with apical aneurism development has also been reported by other investigators. QRS prolongation in (dilated) cardiomyopathies is accepted as a marker of myocardial damage and as a factor of contractile dysfunction. $^{23,24}$ Our study extends the independent prognostic value of this pattern to SCD or surrogates. Patients with abnormally prolonged QRS duration tend to be older, have more frequently a family history of SCD or NSVT during Holter monitoring, and a higher frequency of LV dysfunction (Supplementary Table 1).

The independent prognostic significance of low QRS voltages is interesting but unfortunately of little clinical relevance because of the very low prevalence of this finding (3\%). In cardiomyopathies, low QRS voltages are often secondary to the expansion of myocardial interstitial space (amyloidosis, fibrosis, edema, and flogistic infiltrates) or to diffuse myocellular damage. ${ }^{11}$ In HC, the mechanism has yet to be investigated, but it could be related to a greater degree of myocardial fibrosis. Unfortunately, the absence of magnetic resonance imaging data did not allow us to investigate the phenomenon. No association between low QRS voltages and heart failure development during followup and death due to heart failure and transplant were recorded.

The pseudo-STEMI pattern has never been evaluated in HC. In our study, this pattern (observed in 17\%) is associated with a risk of SCD and surrogates and to major cardiovascular events of 2.28 and 1.66 , respectively, at the multivariable analysis. The high negative predictive value (93\%) is particularly intriguing. The reasons of this finding are not clear, and our study does not have the characteristics necessary to unravel the issue. It is notably that the pattern is not associated with a more severe morphologic or arrhythmic phenotype. Patients with the pseudo-STEMI pattern were younger, more frequently men, and with a higher rate of LV outflow obstruction (Supplementary Table 1). It is reasonable that the peculiar repolarization abnormality could be the expression of a genetically determined ion-channel dysfunction accidentally associated with HC. Some published data are potentially in line with this hypothesis. Lopes et $\mathrm{al}^{25}$ documented a very high number of sarcomeric and nonsarcomeric genetic variants associated with the classic $\mathrm{HC}$ mutations and hypothesized that some of these variants could influence the expression of $\mathrm{HC}$ phenotype. In HC probands, a relation between rare variants in the SCN5A gene and left atrial enlargement at last evaluation or LV outflow obstruction have been reported. ${ }^{25}$ Additionally, SCN5A variants appear to influence the fibrotic process in patients with sarcomeric protein mutations. ${ }^{26}$ A similar explanation (i.e., involving ion channels) has been proposed for the cases of SCD associated with early repolarization in the general population. ${ }^{27,28}$ In our series, however, the prevalence of early repolarization, defined as the sole presence of $\mathbf{J}$ wave (3\%), is decidedly low and prognostically irrelevant. A single study on a small cohort of patients with $\mathrm{HC}^{29}$ reports a prevalence of early 
repolarization (defined as J-point elevation $\geq 0.1 \mathrm{mV}$ in at least 2 consecutive inferior/lateral leads excluding V1-V2$\mathrm{V} 3$ ) of $12 \%$ and found that the presence of a $\mathrm{J}$ wave was more frequent in patients who died suddenly. Prospective studies are required to test these hypothesis.

Beyond the incomplete understanding of the mechanisms, it is noteworthy that when added to the conventional SCD risk factors, electrocardiographic variables, despite their low positive predictive value, improved the risk stratification model (Figure 2), especially the ability to identify subjects at very low risk (annual SCD or surrogates rate in patients without any conventional risk factors or electrocardiographic markers is $0.3 \%$ ). It should be noted that survival curves of patients with/without prolonged QRS tend to diverge soon after the initial observation, differently from what occurs with the pseudo-STEMI pattern. These new observations may be included in the recently proposed algorithm for quantitative 5-year risk calculation.

The main limitations of this study are the retrospective design that may have introduced a selection bias and the relatively small size that may have limited the prognostic significance of the statistical analysis. Also, appropriate ICD activation is a surrogate marker of sudden death and its use for outcome analysis may have led to an overestimation of events. Because of the lack of genetic data, we can only speculate that ion-channel mutations could be associated with the pseudo-STEMI pattern, and further prospective studies are required to investigate this hypothesis.

\section{Disclosures}

The authors have no conflicts of interest to disclose.

\section{Supplementary Data}

Supplementary data associated with this article can be found, in the online version, at http://dx.doi.org/10.1016/j. amjcard.2016.05.023.

1. Authors/Task Force Members; Elliott PM, Anastasakis A, Borger MA, Borggrefe M, Cecchi F, Charron P, Hagege AA, Lafont A, Limongelli G, Mahrholdt H, McKenna WJ, Mogensen J, Nihoyannopoulos P, Nistri S, Pieper PG, Pieske B, Rapezzi C, Rutten FH, Tillmanns C, Watkins H. 2014 ESC guidelines on diagnosis and management of hypertrophic cardiomyopathy: the Task Force for the diagnosis and management of hypertrophic cardiomyopathy of the European Society of Cardiology (ESC). Eur Heart J 2014:35:2733-2779.

2. American College of Cardiology Foundation/American Heart Association Task Force on Practice; American Association for Thoracic Surgery; American Society of Echocardiography; American Society of Nuclear Cardiology; Heart Failure Society of America; Heart Rhythm Society; Society for Cardiovascular Angiography and Interventions; Society of Thoracic Surgeons; Gersh BJ, Maron BJ, Bonow RO, Dearani JA, Fifer MA, Link MS, Naidu SS, Nishimura RA, Ommen SR, Rakowski H, Seidman CE, Towbin JA, Udelson JE, Yancy CW. 2011 ACCF/AHA guideline for the diagnosis and treatment of hypertrophic cardiomyopathy: a report of the American College of Cardiology Foundation/American Heart Association Task Force on Practice Guidelines. J Thorac Cardiovasc Surg 2011;142:153-203.

3. McLeod CJ, Ackerman MJ, Nishimura RA, Tajik AJ, Gersh BJ, Ommen SR. Outcome of patients with hypertrophic cardiomyopathy and a normal electrocardiogram. J Am Coll Cardiol 2009;54:229-233.

4. Montgomery JV, Harris KM, Casey SA, Zenovich AG, Maron BJ. Relation of electrocardiographic patterns to phenotypic expression and clinical outcome in hypertrophic cardiomyopathy. Am J Cardiol 2005:96:270-275.
5. Bongioanni S, Bianchi F, Migliardi A, Gnavi R, Pron PG, Casetta M, Conte MR. Relation of QRS duration to mortality in a communitybased cohort with hypertrophic cardiomyopathy. Am J Cardiol 2007;100:503-506.

6. Spirito P, Bellone P, Harris KM, Bernabo P, Bruzzi P, Maron BJ. Magnitude of left ventricular hypertrophy and risk of sudden death in hypertrophic cardiomyopathy. N Engl J Med 2000;342:1778-1785.

7. Surawicz B, Childers R, Deal BJ, Gettes LS, Bailey JJ, Gorgels A, Hancock EW, Josephson M, Kligfield P, Kors JA, Macfarlane P, Mason JW, Mirvis DM, Okin P, Pahlm O, Rautaharju PM, van Herpen G, Wagner GS, Wellens H; American Heart Association Electrocardiography and Arrhythmias Committee, Council on Clinical Cardiology; American College of Cardiology Foundation; Heart Rhythm Society. AHA/ACCF/HRS recommendations for the standardization and interpretation of the electrocardiogram: part III: intraventricular conduction disturbances: a scientific statement from the American Heart Association Electrocardiography and Arrhythmias Committee, Council on clinical Cardiology; the American College of Cardiology Foundation; and the Heart Rhythm Society. Endorsed by the International Society for Computerized Electrocardiology. J Am Coll Cardiol 2009;53:976-981.

8. Casale PN, Devereux RB, Kligfield P, Eisenberg RR, Miller DH, Chaudhary BS, Phillips MC. Electrocardiographic detection of left ventricular hypertrophy: development and prospective validation of improved criteria. J Am Coll Cardiol 1985;6:572-580.

9. Dollar AL, Roberts WC. Usefulness of total 12-lead QRS voltage compared with other criteria for determining left ventricular hypertrophy in hypertrophic cardiomyopathy: analysis of 57 patients studied at necropsy. Am J Med 1989;87:377-381.

10. Konno T, Shimizu M, Ino H, Yamaguchi M, Terai H, Uchiyama K, Oe K, Mabuchi T, Kaneda T, Mabuchi H. Diagnostic value of abnormal Q waves for identification of preclinical carriers of hypertrophic cardiomyopathy based on a molecular genetic diagnosis. Eur Heart $J$ 2004;25:246-251.

11. Rapezzi C, Merlini G, Quarta CC, Riva L, Longhi S, Leone O, Salvi F, Ciliberti P, Pastorelli F, Biagini E, Coccolo F, Cooke RM, BacchiReggiani L, Sangiorgi D, Ferlini A, Cavo M, Zamagni E, Fonte ML, Palladini G, Salinaro F, Musca F, Obici L, Branzi A, Perlini S. Systemic cardiac amyloidoses: disease profiles and clinical courses of the 3 main types. Circulation 2009;120:1203-1212.

12. Rautaharju PM, Surawicz B, Gettes LS, Bailey JJ, Childers R, Deal BJ, Gorgels A, Hancock EW, Josephson M, Kligfield P, Kors JA, Macfarlane P, Mason JW, Mirvis DM, Okin P, Pahlm O, van Herpen G, Wagner GS, Wellens H; American Heart Association Electrocardiography and Arrhythmias Committee, Council on Clinical Cardiology; American College of Cardiology Foundation; Heart Rhythm Society. $\mathrm{AHA} / \mathrm{ACCF} / \mathrm{HRS}$ recommendations for the standardization and interpretation of the electrocardiogram: part IV: the ST segment, T and U waves, and the QT interval: a scientific statement from the American Heart Association Electrocardiography and Arrhythmias Committee, Council on Clinical Cardiology; the American College of Cardiology Foundation; and the Heart Rhythm Society. Endorsed by the International Society for Computerized Electrocardiology. J Am Coll Cardiol 2009;53:982-991.

13. Gironi G, Ferrari M, Brugi A. The positive "giant" $\mathrm{T}$ waves in the precordial leads: their frequency and significance in a study made on 7118 tracings. Folia Cardiol 1966;25:215-243.

14. Task Force on the Management of ST-Segment Elevation Acute Myocardial Infarction of the European Society of Cardiology (ESC); Steg PG, James SK, Atar D, Badano LP, Blömstrom-Lundqvist C, Borger MA, Di Mario C, Dickstein K, Ducrocq G, Fernandez-Aviles F, Gershlick AH, Giannuzzi P, Halvorsen S, Huber K, Juni P, Kastrati A, Knuuti J, Lenzen MJ, Mahaffey KW, Valgimigli M, van 't Hof A, Widimsky P, Zahger D. ESC guidelines for the management of acute myocardial infarction in patients presenting with ST-segment elevation. Eur Heart J 2012;33:2569-2619.

15. Maron MS, Olivotto I, Betocchi S, Casey SA, Lesser JR, Losi MA, Cecchi F, Maron BJ. Effect of left ventricular outflow tract obstruction on clinical outcome in hypertrophic cardiomyopathy. $N$ Engl J Med 2003:348:295-303.

16. Pennacchini E, Musumeci MB, Conte MR, StÃllberger C, Formisano F, Bongioanni S, Francia P, Volpe M, Autore C. Electrocardiographic evolution in patients with hypertrophic cardiomyopathy who develop a left ventricular apical aneurysm. J Electrocardiol 2015;48:818-825. 
The American Journal of Cardiology (www.ajconline.org)

17. Yi G, Elliott P, McKenna WJ, Prasad K, Sharma S, Guo XH, Camm AJ, Malik M. QT dispersion and risk factors for sudden cardiac death in patients with hypertrophic cardiomyopathy. Am J Cardiol 1998;82: 1514-1519.

18. Yi G, Poloniecki J, Dickie S, Elliott PM, Malik M, McKenna WJ. Is QT dispersion associated with sudden cardiac death in patients with hypertrophic cardiomyopathy? Ann Noninvasive Electrocardiol 2001;6:209-215.

19. Maron BJ, Leyhe MJ III, Casey SA, Gohman TE, Lawler CM, Crow RS, Maron MS, Hodges M. Assessment of QT dispersion as a prognostic marker for sudden death in a regional nonreferred hypertrophic cardiomyopathy cohort. Am J Cardiol 2001;87:114-115.

20. Johnson JN, Grifoni C, Bos JM, Saber-Ayad M, Ommen SR, Nistri S, Cecchi F, Olivotto I, Ackerman MJ. Prevalence and clinical correlates of QT prolongation in patients with hypertrophic cardiomyopathy. Eur Heart J 2011;32:1114-1120.

21. Gray B, Ingles J, Medi C, Semsarian C. Prolongation of the QTc interval predicts appropriate implantable cardioverter-defibrillator therapies in hypertrophic cardiomyopathy. JACC Heart Fail 2013;1: $149-155$.

22. Ostman-Smith I, Wisten A, Nylander E, Bratt EL, Granelli Ad, Oulhaj A, Ljungström E. Electrocardiographic amplitudes: a new risk factor for sudden death in hypertrophic cardiomyopathy. Eur Heart J 2010;31:439-449.

23. Hofmann M, Bauer R, Handrock R, Weidinger G, Goedel-Meinen L. Prognostic value of the QRS duration in patients with heart failure: a subgroup analysis from 24 centers of Val-HeFT. J Card Fail 2005;11: $523-528$.

24. Baldasseroni S, Opasich C, Gorini M, Lucci D, Marchionni N, Marini M, Campana C, Perini G, Deorsola A, Masotti G, Tavazzi L, Maggioni AP; Italian Network on Congestive Heart Failure Investigators. Left bundle-branch block is associated with increased 1-year sudden and total mortality rate in 5517 outpatients with congestive heart failure: a report from the Italian network on congestive heart failure. Am Heart $J$ 2002;143:398-405.

25. Lopes LR, Syrris P, Guttmann OP, O’Mahony C, Tang HC, Dalageorgou C, Jenkins S, Hubank M, Monserrat L, McKenna WJ, Plagnol $\mathrm{V}$, Elliott PM. Novel genotype-phenotype associations demonstrated by high-throughput sequencing in patients with hypertrophic cardiomyopathy. Heart 2015;101:294-301.

26. Hao X, Zhang Y, Zhang X, Nirmalan M, Davies L, Konstantinou D, Yin F, Dobrzynski H, Wang X, Grace A, Zhang H, Boyett M, Huang CL, Lei M. TGF- $\beta 1$-mediated fibrosis and ion channel remodeling are key mechanisms in producing the sinus node dysfunction associated with SCN5A deficiency and aging. Circ Arrhythm Electrophysiol 2011;4:397-406.

27. Tikkanen JT, Anttonen O, Junttila MJ, Aro AL, Kerola T, Rissanen HA, Reunanen A, Huikuri HV. Long-term outcome associated with early repolarization on electrocardiography. N Engl J Med 2009;361: $2529-2537$.

28. Hassaguerre M, Derval N, Sacher F, Jesel L, Deisenhofer I, de Roy L, Pasquié JL, Nogami A, Babuty D, Yli-Mayry S, De Chillou C, Scanu P, Mabo P, Matsuo S, Probst V, Le Scouarnec S, Defaye P, Schlaepfer J, Rostock T, Lacroix D, Lamaison D, Lavergne T, Aizawa Y, Englund A, Anselme F, O’Neill M, Hocini M, Lim KT, Knecht S, Veenhuyzen GD, Bordachar P, Chauvin M, Jais P, Coureau G, Chene G, Klein GJ, Clémenty J. Sudden cardiac arrest associated with early repolarization. N Engl J Med 2008;358:2016-2023.

29. Li Y, Mao J, Yan Q, Qi S, Liu X, Tan C, Zhang Y, Shi L, Tian Y, Wu Y, Zeng Y, Wang J, Chu J, Ma C, Liu X, Yang X. J wave is associated with increased risk of sudden cardiac arrest in patients with hypertrophic cardiomyopathy. J Int Med Res 2013;41:1281-1290. 